\title{
Attenuating resonant behavior of a tied arch railway bridge using increased hanger damping
}

\author{
A. Andersson \& R. Karoumi \\ Division of Structural Engineering and Bridges, KTH Royal Institute of Technology
}

\begin{abstract}
In this paper, dynamic analyses and field measurements of a tied arch railway bridge is presented. Excessive vibrations of the hangers were obtained, caused by resonance during train passages. The resulting increase of the stress level and number of stress cycles were shown to decrease the fatigue service life significantly. The most critical section is a threaded turnbuckle connection of the hangers. Due to low damping of the hangers, more than $50 \%$ of the cumulative fatigue damage was related to free vibrations after train passage. Passive dampers were installed to attenuate the vibrations by means of increased damping. A combination of field measurements and numerical models are used to investigate the behavior of the bridge and the impact of increased hanger damping.
\end{abstract}

\section{INTRODUCTION}

There is a constant demand on the railway authorities to increase both the allowable axle loads and the allowable speed on existing railway lines. An increased utilization of the bridges can sometimes be justified based on refined capacity assessments and field measurements.

In design of railway bridges, dynamic effects are most often accounted for by dynamic amplification factors (DAF) of the static response. This does not account for resonant behavior. Only for bridges on high-speed lines (defined as an allowable speed more than $200 \mathrm{~km} / \mathrm{h}$ ), separate dynamic calculations are required.

A refined dynamic assessment of a tied arch railway bridge is presented. The project was initiated since excessive vibrations of the hangers were detected. Based on field measurements and numerical simulations, the remaining fatigue service life of the hangers was estimated, further presented in Andersson \& Malm (2004) and Malm \& Andersson (2006). An existing stabilizing system was later replaced with passive dampers, mounted on the longer hangers, Hortmanns \& Schäfer (2005) and Hortmanns (2005).

In this paper, some of the previous field measurements have been reanalyzed and used for updating a simplified 2D finite element model of the bridge. Also, the effect of increased damping measured by Hortmanns \& Schäfer (2005) after installation of the passive dampers are analyzed.

\section{THE BRIDGE}

The bridge was built in 1959 as is designed as a single span tied arch railway bridge. A photo of the bridge is presented in Figure 1. The mid-support is a remain from the previous bridge and is not utilized.

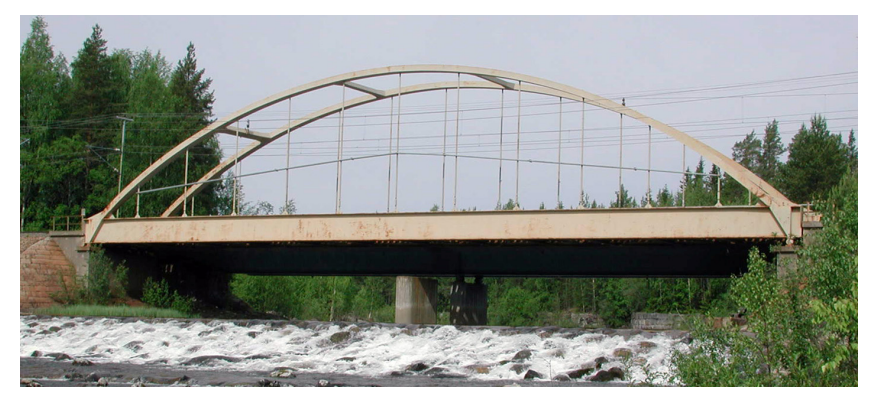

Figure 1. View of the Ljungan railway bridge.

The deck is designed as an unballasted steel grillage consisting of main beams, cross beams and stringers. The wooden sleepers are supported directly by the stringers. A cross-section of the deck is illustrated in Figure 2. The distance between the cross-beams is $3.75 \mathrm{~m}$, same as for the hangers. The hangers consists of solid steel rods with a diameter of $80 \mathrm{~mm}$ at the threaded section. The arch has a circular shape with a radius of $31.9 \mathrm{~m}$ and a height of $8.9 \mathrm{~m}$, measured from the top of the main beam to the arch centre line. More details regarding the geometry can be found in Andersson \& Malm (2004). 


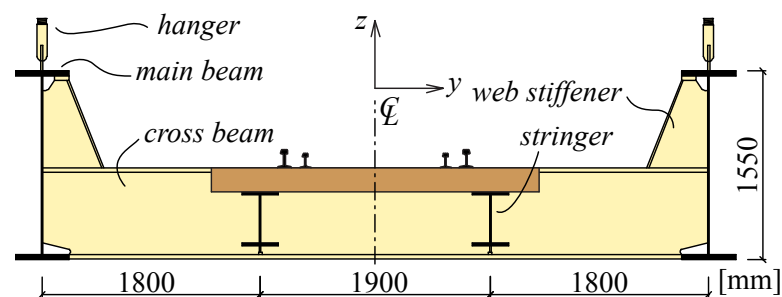

Figure 2. Cross-section of the grillage deck.

Already in the early 1980 's, excessive vibration of the hangers was noticed. A system of diagonal RHS-beams (Rectangular Hollow Section) was installed to stabilize the hangers. These beams can be seen in Figure 1. In 2005, the RHS-beams were replaced with passive dampers on hangers no. $3-9$ on each side of the bridge. The hangers are numbered 1 to 11 where 1 is the shortest and 6 the longest.

\section{FIELD MEASUREMENTS}

\subsection{Instrumentation}

Field measurements were carried out in June 2003, comprising 16 strain gauges and 12 accelerometers, mounted on hanger 2 to 5 . During the measurements, the stabilizing system of RHS-beams was removed. The position of the gauges and details of the hangers are presented in Figure 3. The total length $L_{\mathrm{h}}$ and the position of the accelerometers $L_{\mathrm{a}}$ are given in Table 1. At each position, three accelerometers are mounted together, measuring in $x y z$ directions.

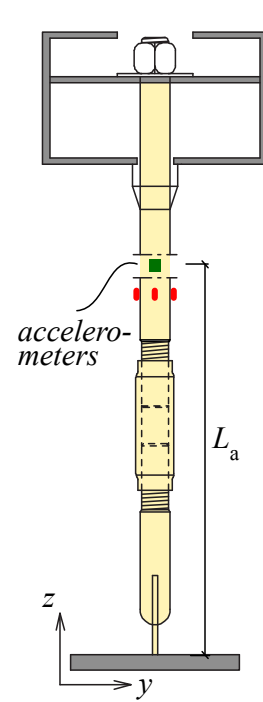

a)

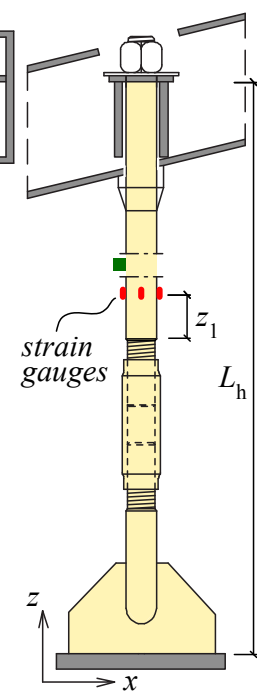

b)

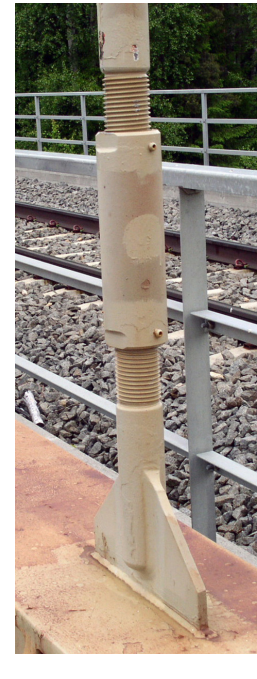

c)
Figure 3. Detail of the hangers, a) section across the bridge, b) section along the bridge, c) detail of the turn buckle connection.

Table 1. Length of the hangers $L_{\mathrm{h}}$ (according to original drawings) and position of accelerometers $L_{\mathrm{a}}$, rounded to $5 \mathrm{~cm}$.

\begin{tabular}{ccccccc} 
Hanger: & 1 & 2 & 3 & 4 & 5 & 6 \\
\hline$L_{\mathrm{h}}(\mathrm{m}):$ & 1.30 & 3.54 & 5.20 & 6.30 & 6.95 & 7.15 \\
$L_{\mathrm{a}}(\mathrm{m}):$ & - & 1.55 & 1.90 & 2.15 & 2.30 & -
\end{tabular}

Four strain gauges were instrumented at each of the studied hangers, positioned $z_{1}=100 \mathrm{~mm}$ above the threaded section and spaced $90^{\circ}$ apart along the perimeter of the hanger. The notation of the strain gauges follows Figure 4. Gauge e1, e5, e9, e13 are closest to the track.

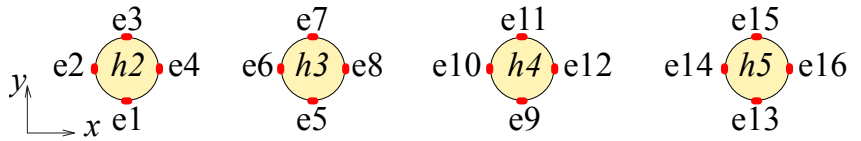

Figure 4. Numbering of the strain gauges on hanger 2 to 5.

Two different data acquisition systems were used, HBM MGCPlus for the strain gauges and a Sony $P C 216 A X$ with an $U N O-M W L 006$ amplifier for the accelerometers. The sampling frequency was set to $2 \mathrm{kHz}$ for the strain gauges and $6 \mathrm{kHz}$ for the accelerometers. To avoid overloading, an analogue $20 \mathrm{~Hz}$ low-pass filter $(P C P-848)$ was used for the accelerometers. To synchronize the signals from the two systems, strain gauge no. $1,2,15,16$ were connected to both systems.

A total of six train passages were recorded, four freight trains and two passenger trains. In addition, free vibration tests were performed to determine the natural frequencies of the hangers without disturbance from passing trains.

\subsection{Natural frequencies and damping}

The natural frequencies and damping ratios of the hangers were estimated based on free vibration tests. Each hanger was excited by a swift knock in each direction. Based on a Maximum Likelihood estimate of the free decay of motion, the results in Table 2 Table 3 are obtained. Similar measurements reported by Hortmanns \& Schäfer (2005) generally show very good agreement. The average difference in estimated frequency was about $0.1 \%$. The difference of individual damping ratio scatters significantly, but the average for all hangers is $0.2 \%$, both from Hortmanns \& Schäfer (2005) and in Table 3.

Table 2. Estimated natural frequencies, based on free vibration measurements.

\begin{tabular}{ccccc} 
Hanger & $f_{1, \mathrm{x}}(\mathrm{Hz})$ & $f_{2, \mathrm{x}}(\mathrm{Hz})$ & $f_{1, \mathrm{y}}(\mathrm{Hz})$ & $f_{2, \mathrm{y}}(\mathrm{Hz})$ \\
\hline 2 & 16.0 & 44.9 & 10.9 & 34.0 \\
3 & 7.9 & 23.1 & 6.1 & 18.9 \\
4 & 7.2 & 19.2 & 6.0 & 16.5 \\
5 & 4.3 & 13.5 & 3.6 & 11.4
\end{tabular}

Table 3. Estimated damping ratios, based on free vibration measurements.

\begin{tabular}{ccccc} 
Hanger & $\zeta_{1, \mathrm{x}}(\%)$ & $\zeta_{2, \mathrm{x}}(\%)$ & $\zeta_{1, \mathrm{y}}(\%)$ & $\zeta_{2, \mathrm{y}}(\%)$ \\
\hline 2 & 0.33 & 0.18 & 0.14 & 0.46 \\
3 & 0.16 & 0.22 & 0.42 & 0.16 \\
4 & 0.09 & 0.08 & 0.14 & 0.19 \\
5 & 0.15 & 0.05 & 0.30 & 0.24
\end{tabular}




\subsection{Plane stress components}

The total stress in the hangers is due to the combination of axial forces and bending moments in two directions. Since four strain gauges are available at each section, the system is over-determined. This facilitates including the torsion component, resulting in Equation (1). The torsion is however found to give small contribution in stresses and mainly serves as indication that no torsion is present. The stresses due to axial force and bending moments are similar for either including torsion or using any given combination of three strain gauges.

$\sigma=\frac{N}{A} \pm \frac{M_{\mathrm{x}}}{W_{\mathrm{x}}} \pm \frac{M_{y}}{W_{y}} \pm \frac{T}{J} r$

During train passage, resonant behavior of several hangers was obtained. Due to very low damping, this results in significant increase of both stress range and number of stress cycles. The stress components of hanger 5 during passage of a freight train are presented in Figure 5. The train consists of one locomotive and 19 wagons, transporting steel ingot.

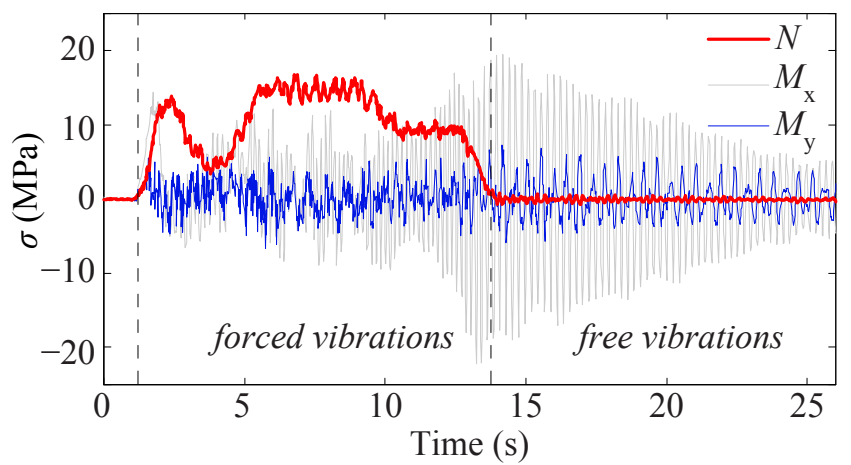

Figure 5. Stress components in hanger 5 during passage of a freight train.

During the train passage, the main stress contribution is due to the axial force. For the following free vibrations however, bending stresses longitudinal to the track is of the same amplitude. The hanger is mainly oscillating with its first natural frequency at $4.3 \mathrm{~Hz}$, causing a significant amount of stress cycles.

\subsection{Cumulative fatigue damage}

The most fatigue critical part of the hangers is the threaded section at the turn buckle, illustrated in Figure 3. According to Eurocode 3 (CEN, 2005), threaded bolts are assigned a detail category $C=50$. This corresponds to a fatigue service life of 2 million stress cycles at a constant stress range of $50 \mathrm{MPa}$. Due to size effects, a correction factor $k_{\mathrm{s}}$ shall be accounted for, if the diameter is larger than $30 \mathrm{~mm}$. for the present case $k_{\mathrm{s}}=0.8$, resulting in $C=40$. Similar results are obtained using the Swedish design code BSK 07, Boverket (2007).
Palmgren-Miners cumulative damage rule (Palmgren, 1924 and Miner, 1945) is used according to Equation (2), where $n_{\mathrm{E} i}$ is the number of stress cycles with a stress range $\Delta \sigma_{\mathrm{R} i}$ and $N_{\mathrm{R} i}$ is the maximum number of stress cycles until failure for a constant stress range. The fatigue strength is governed by Equation (3). The stress range shall be multiplied with a safety factor $\gamma_{\mathrm{Mf}}=1.35$. The effective area in the threaded section is $74 \mathrm{~mm}$ compared to the gross diameter of $80 \mathrm{~mm}$ at the position of the strain gauges. Since most of the fatigue-induced stresses are due to bending, the measured strains are multiplied with the factor $(80 / 74)^{3}=1.26$.

$$
D_{\mathrm{d}}=\sum_{i=1}^{n} \frac{n_{\mathrm{E} i}}{N_{\mathrm{R} i}}
$$

$$
\begin{array}{ll}
\Delta \sigma_{\mathrm{R}}^{\mathrm{m}} N_{\mathrm{R}}=\Delta \sigma_{\mathrm{C}}^{\mathrm{m}} 2 \times 10^{6}, & m=3, N \leq 5 \times 10^{6} \\
\Delta \sigma_{\mathrm{R}}^{\mathrm{m}} N_{\mathrm{R}}=\Delta \sigma_{\mathrm{C}}^{\mathrm{m}} 5 \times 10^{6}, & m=5,5 \times 10^{6} \leq N \leq 10^{8}
\end{array}
$$

The stress collective is calculated using a Rainflow counting algorithm according to Rychlik (1987) and the measured response of the freight train in Figure 5. The theoretical fatigue service life is obtained when $D_{\mathrm{d}}=1$ and the corresponding number of train passages is presented in Table 4 . Two cases are studied, $\gamma_{\mathrm{Mf}}=1.35$ and $\gamma_{\mathrm{Mf}}=1.0$. The fatigue service life is proportional to $\gamma_{\mathrm{Mf}}^{\mathrm{m}}$, for the present case corresponding to an average reduction factor of 3 . A parametric study of the influence of the safety factor on the fatigue service life is shown in Leander et al. (2010). Assuming 2 similar trains per day, results in a total service life of merely 20 years for hanger 5 , provided that no other trains contribute to fatigue. If instead using $\gamma_{\mathrm{Mf}}=1.0$, the corresponding service life would be 50 years. The fatigue damage due to free vibrations was negligible for hanger 2 and 3 . For hanger 4 and 5 however, it constituted $10 \%$ and $60 \%$ respectively. No knowledge of hanger 6 is available since it was not instrumented.

Table 4. Number of train passages until $D_{\mathrm{d}}=1$.

\begin{tabular}{crr} 
Hanger: & $\gamma_{\mathrm{Mf}}=1.35$ & $\gamma_{\mathrm{Mf}}=1.0$ \\
\hline 2 & 281400 & 831300 \\
3 & 113000 & 402200 \\
4 & 33400 & 105900 \\
5 & 13400 & 36300
\end{tabular}

\subsection{Accelerations and displacements}

To attenuate the vibrations of mainly the longer hangers, a system of passive dampers was installed in 2005, Hortmanns (2005). One of the design conditions for the dampers was the amplitude of displacement of the hangers.

The displacement of the hangers was estimated based on the measured accelerations, positioned according to Table 1 , at about $0.4 L_{\mathrm{h}}$. A Newmark time 
integration routine according to Equation (4) was adopted, using $\beta=0.25$ and $\gamma=0.5$ according to the trapezoidal rule. The measured acceleration had previously been subjected to an analogue low-pass filter at $20 \mathrm{~Hz}$. To attenuate deviating trends due to time integration, a digital high-pass filter at $0.5 \mathrm{~Hz}$ was used. Since the lowest measured natural frequency of the hangers was $3.6 \mathrm{~Hz}$ this does not influence the resonant behaviour. Global displacements of the bridge during train passage may however not be obtained.

$$
\begin{aligned}
& \dot{u}_{\mathrm{i}}=\dot{u}_{\mathrm{i}-1}+(1-\gamma) \Delta t \ddot{u}_{\mathrm{i}-1}+\gamma \Delta t \ddot{u}_{\mathrm{i}}, \\
& u_{\mathrm{i}}=u_{\mathrm{i}-1}+\Delta t \dot{u}_{\mathrm{i}-1}+(0.5-\beta) \Delta t^{2} \ddot{u}_{\mathrm{i}-1}+\beta \Delta t^{2} \ddot{u}_{\mathrm{i}}
\end{aligned}
$$

An estimation of the longitudinal displacement of hanger 5 due to the previous freight train passage is presented in Figure 6. Except of a few high oscillations during the entrance of the train on the bridge, the peak displacement is about $3.5 \mathrm{~mm}$. For all other instrumented hangers, the peak displacement is estimated during the initial free vibration phase, presented in Table 5 .

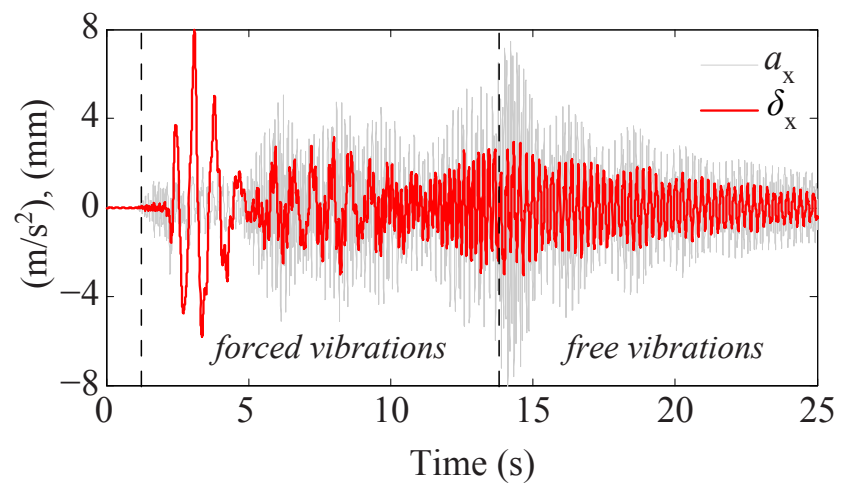

Figure 6. Acceleration and estimated displacements of hanger 5 during passage of a freight train.

Table 5. Estimated peak displacements of the hangers during passage of a freight train.

\begin{tabular}{ccc} 
Hanger & $\delta_{\mathrm{x}}(\mathrm{mm})$ & $\delta_{\mathrm{y}}(\mathrm{mm})$ \\
\hline 2 & 1.6 & 2.9 \\
3 & 2.4 & 4.4 \\
4 & 3.5 & 3.6 \\
5 & 8.0 & 2.9
\end{tabular}

\section{FINITE ELEMENT ANALYSIS}

\subsection{D-model}

The dynamic behavior of the bridge has been simulated using FE-models. A detailed 3D model has been presented in Andersson \& Malm (2004) and Malm \& Andersson (2005). In the following, a simplified 2D model is instead studied, only accounting for the longitudinal motions.
The FE-model is created using the commercial FE-package SOLVIA03. Half of the bridge is included, comprising one arch, one main beam, one stringer and all hangers on one side. All components are modeled using Euler-Bernoulli beam elements, except the cross beams that are modeled as vertical springs. The spring stiffness is calculated to produce the same vertical displacement as a simply supported beam subjected to two point loads. The model is illustrated in Figure 7. The detailed connections of the model are shown in Figure 8. All elements are modeled along its centre line. To obtain the correct length of the hangers, the connection with the main beam is extended using a rigid link, and is considered as fully clamped. The connection with the arch is however considered hinged. This is accomplished by releasing the rotational degree of freedom belonging to the end node of each hanger.

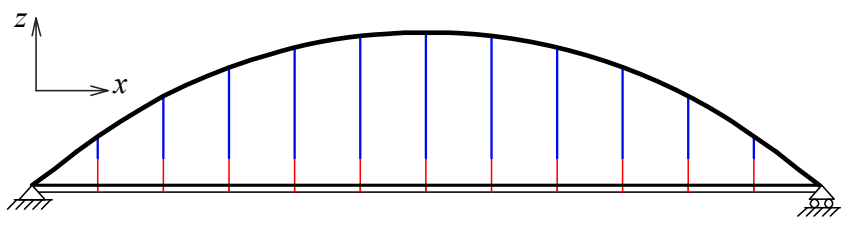

Figure 7. Elevation of the 2D FE-model.

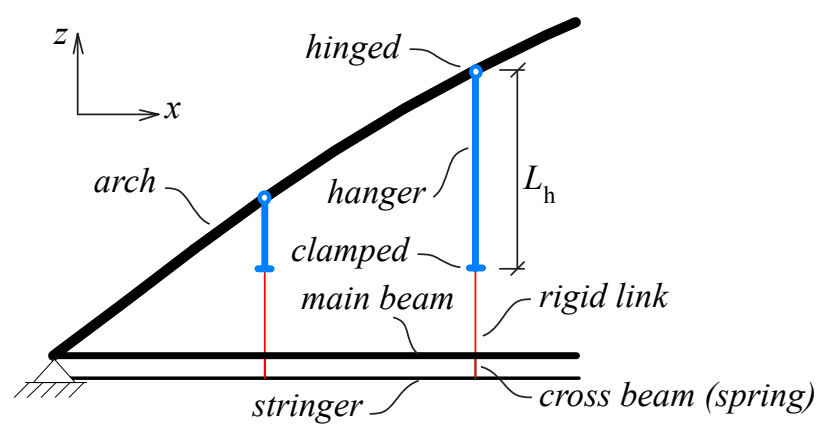

Figure 8. Details of the FE-model.

\subsection{Natural frequencies}

An Eigen-value analysis is performed to calculate the frequencies of the structure. The permanent load is applied prior to the Eigen-value analysis, to account for the axial stress in of the hangers. The results are presented in Table 6.

Table 6. Natural frequencies of the hangers, predicted by the 2D FE-model and a comparison with measured results.

\begin{tabular}{ccc|cc} 
& \multicolumn{2}{c|}{ FEM } & \multicolumn{2}{c}{ FEM / measured } \\
Hanger & $f_{1, \mathrm{x}}(\mathrm{Hz})$ & $f_{2, \mathrm{x}}(\mathrm{Hz})$ & $f_{1, \mathrm{x}}(-)$ & $f_{2, \mathrm{x}}(-)$ \\
\hline 2 & 16.1 & 50.5 & 0.99 & 0.89 \\
3 & 7.8 & 23.8 & 1.00 & 0.97 \\
4 & 7.4 & 19.8 & 0.97 & 0.97 \\
5 & 4.5 & 13.4 & 0.95 & 1.01 \\
6 & 4.3 & 12.7 & - & -
\end{tabular}


Initially, the frequencies for hanger 4 was $f_{1 \mathrm{x}}=$ $5.4 \mathrm{~Hz}$ and $f_{2 \mathrm{x}}=16.3 \mathrm{~Hz}$, in poor agreement with the measured data. If instead assuming the arch-tohanger connection as fully clamped, the results in Table 6 was obtained. For sake of comparison, this assumption is used in further analysis. Since the hangers are relatively independent on each other, the corresponding hanger 8 is still assumed hinged.

The two lowest global modes of the bridge are illustrated in Figure 9. The global modes generally excite all hangers, especially if the arch and the main beam are out of phase.
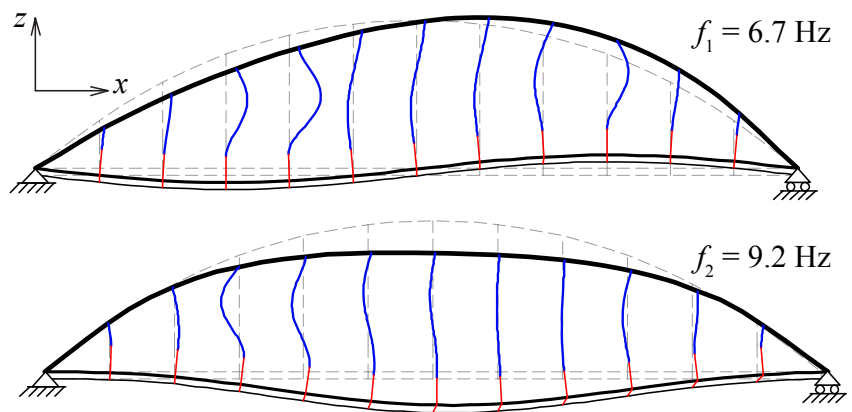

Figure 9. The two lowest global modes of vibration.

\subsection{Dynamic analysis of passing trains}

The 2D FE-model has been used for dynamic analysis of passing trains. The train is modeled as vertical point loads only, travelling along the stringer beam. Since the model only comprises half of the bridge, half of the axle load is applied. The pre-stress of the hangers due to permanent load is accounted for, as well as increased load during train passage. Hence the analysis is considered nonlinear. For this reason, a direct time integration scheme is employed instead of modal superposition. One back draw of the direct time integration is that constant modal damping can not be used. Instead, a frequency dependent material damping according to Equation (5) is used, often denoted as Rayleigh damping. It consists of two components, $\alpha$ for mass proportional damping and $\beta$ for stiffness proportional damping, Equation (6). For the present case, a critical damping ratio $\zeta=0.2 \%$ is used, fitted by the frequencies $f_{\mathrm{n}}=4 \mathrm{~Hz}$ and $f_{\mathrm{m}}=$ $20 \mathrm{~Hz}$.

$\left\{\begin{array}{l}\alpha \\ \beta\end{array}\right\}=\frac{2 \zeta}{\omega_{\mathrm{n}}+\omega_{\mathrm{m}}}\left\{\begin{array}{c}\omega_{\mathrm{n}} \omega_{\mathrm{m}} \\ 1\end{array}\right\}$

$\mathbf{c}=\alpha \mathbf{m}+\beta \mathbf{k}$

The train set is composed of one locomotive and 19 wagons. Both the locomotive and the wagons consists of two bogies with two axels in each bogie. For the locomotive (Rc4), the axle distance is $2.7 \mathrm{~m}$, the bogie distance $7.7 \mathrm{~m}$, the total length $15.5 \mathrm{~m}$ and the load $195 \mathrm{kN} / \mathrm{axle}$. Standardized freight train wagons are assumed according to load class D2.
This corresponds to an axle distance $1.8 \mathrm{~m}$, bogie distance $9.2 \mathrm{~m}$, length $14.0 \mathrm{~m}$ and the load $225 \mathrm{kN} /$ axle. The train speed is varied between 60 to $140 \mathrm{~km} / \mathrm{h}$ in increments of $10 \mathrm{~km} / \mathrm{h}$. Time history data is extracted in positions corresponding to the field measurements.

The most pronounced resonance is obtained at $110 \mathrm{~km} / \mathrm{h}$. In Figure 10, the longitudinal displacement of hanger 5 is presented. The results from the simplified 2D FE-model agrees reasonably well with the measurements, considering that the train loading is not readily known and that the time integration of measured acceleration may be uncertain.

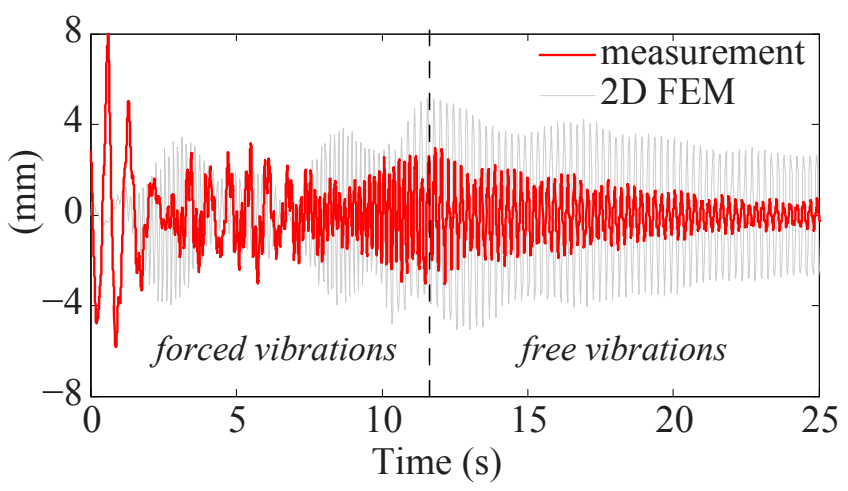

Figure 10. Displacement of hanger 5, comparison of integration of measured acceleration and simulation results from the $2 \mathrm{D}$ FE-model.

In Figure 11, the stress components of hanger 6 are presented for the same train passage. Resonance of the hanger causes excessive bending stresses. In the simulation, all wagons are equally loaded and have the same axle configuration. Comparing the axial stress component of Figure 5, the train from the field measurement was likely unevenly loaded.

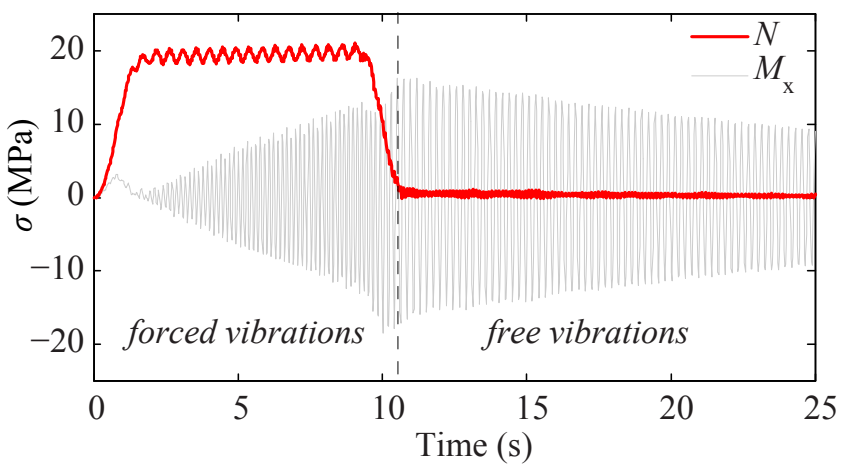

Figure 11. Stress components in hanger 6 during passage of a freight train (type D2 with 19 wagons).

\subsection{Increased hanger damping}

To attenuate the resonant behavior and resulting bending stresses of the hangers, passive dampers was installed on hanger 3 to 9 on each side of the bridge. The installation of the dampers and additional measurements is reported in Hortmanns (2005). The dampers consists of cylindrical shells, 
each containing four pendulums partly surrounded by a silicone oil. The diameter of the dampers is $310 \mathrm{~mm}$ and the height $350 \mathrm{~mm}$. Based on free vibration tests, the damping ratio was estimated for each hanger. In average, the damping in the longitudinal direction ranged between $1.8-6.4 \%$, with an average of $3.6 \%$.

The previous 2D FE-model has been updated to account for the increased hanger damping. Since the resulting damping is available, an increased Rayleigh damping using $\zeta=3.5 \%$ for all hangers is assumed. The additional mass of the dampers neglected.

In Figure 12, the stress components for hanger 6 calculated with the 2D FE-model is presented, including the updated damping. The bending stresses is attenuated significantly due to the increased damping.

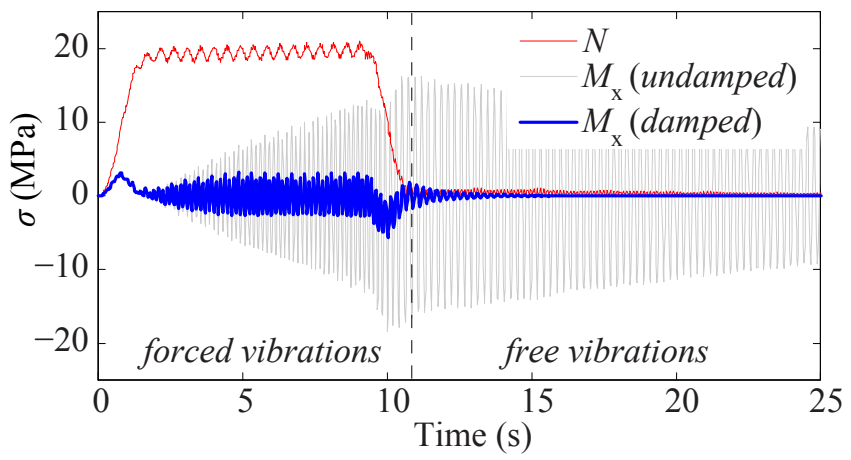

Figure 12. Stress components in hanger 6 during passage of a freight train (type D2 with 19 wagons), influence of increased hanger damping.

\section{CONCLUSION}

In this paper, the dynamic behavior of a tied arch railway bridge has been analyzed by means of data from field measurements and a 2D FE-model. The measurements showed that the hangers had very low damping, in average $0.2 \%$. This can be compared to CEN (2003), recommending $0.5 \%$ damping for steel bridges. Resonant behavior was measured, causing excessive increase in bending stresses. Due to the low damping, both the stress magnitude and number of stress cycles affected the fatigue service life. For one hanger, more than $50 \%$ of the fatigue service life was found related to free vibrations.

A 2D FE-model of the bridge was used to compare measured frequencies, displacements and stresses of the hangers. Assuming the hangers to be fully clamped at the connection with the main beam and hinged at the connection with the arch generally produced the best agreement with measured data. For one hanger however, better agreement was found if assuming the upper connection as fixed.

The displacements and stresses estimated by the FE-model was generally in good agreement with the measured data, considering that the train configuration from the field measurements was not known in detail.

To attenuate the resonant behavior, passive dampers were installed in 2005. Based on free vibration tests, the damping ratio after installation was estimated, reported in Hortmanns (2005). The resulting damping was increased to about $2-6 \%$. The FE-model was updated using an average damping of $3.5 \%$. The result from the model showed that the resonant behaviour was attenuated significantly, especially for the bending stresses.

\section{REFERENCES}

Andersson, A., Malm R. (2004). Measurement Evaluation and FEM Simulation of Bridge Dynamics. MSc. Thesis, KTH Royal Institute of Technology.

Boverket, 2007. Swedish handbook for design of steel structures, BSK 07. In Swedish.

CEN (2003). Eurocode 1: Actions on structures Part 2: Traffic loads on bridge. EN 1991-2:2003.

CEN (2005). Eurocode 3: Design of steel structures - Part 1-9: Fatigue. EN 1993-1-9:2005.

Hortmanns, M., Schäfer, N. (2005). Ljungan Bridge, Ånge Sweden - Full Scale Measurements. Tech. report, Prof. Sedlacek \& Partner (unpublished).

Hortmanns, M. (2005). Ljungan Bridge, Ånge Sweden - Design of dampers for the hangers 3 to 6 . Tech. report, Prof. Sedlacek \& Partner (unpublished).

Leander, J., Andersson, A., Karoumi, R. (2010). Monitoring and enhanced fatigue evaluation of a steel railway bridge. Engineering Structures 32, pp. 854-863.

Malm, R., Andersson, A. (2006). Field testing and simulation of dynamic properties of a tied arch railway bridge. Engineering Structures 28, pp. 143-152.

Miner, M. A. (1945). Cumulative damage in fatigue. Journal of Applied Mechanics, 23(1).

Palmgren, A. (1924). Die Lebensdauer von Kugellagern. VDI Zeitschrift, 68(14).

Rychlik, I. (1987). A new definition of the rainflow cycle counting method. International Journal of Fatigue, 9(2). 